\title{
Analysis of the leaf methylomes of parents and their hybrids provides new insight into hybrid vigor in Populus deltoides
}

\author{
Ming Gao ${ }^{1,2+}$, Qinjun Huang ${ }^{1,2+}$, Yanguang Chu ${ }^{1,2}$, Changjun Ding ${ }^{1,2}$, Bingyu Zhang ${ }^{1,2}$, Xiaohua Su S $^{1, *}$ \\ From International Symposium on Quantitative Genetics and Genomics of Woody Plants \\ Nantong, China. 16-18 August 2013
}

\begin{abstract}
Background: Plants with heterosis/hybrid vigor perform better than their parents in many traits. However, the biological mechanisms underlying heterosis remain unclear. To investigate the significance of DNA methylation to heterosis, a comprehensive analysis of whole-genome DNA methylome profiles of Populus deltoides cl.'55/65' and '10/17' parental lines and their intraspecific F1 hybrids lines was performed using methylated DNA immunoprecipitation (MeDIP) and high-throughput sequencing.

Results: Here, a total of 486.27 million reads were mapped to the reference genome of Populus trichocarpa, with an average unique mapping rate of $57.8 \%$. The parents with similar genetic background had distinct DNA methylation levels. F1 hybrids with hybrid vigor possessed non-additive DNA methylation level (their levels were higher than mid-parent values). The DNA methylation levels in promoter and repetitive sequences and transposable element of better-parent F1 hybrids and parents and lower-parent F1 hybrids were different. Compared with the maternal parent, better-parent F1 hybrids had fewer hypermethylated genes and more hypomethylated ones. Compared with the paternal parent and lower-parent L1, better-parent F1 hybrids had more hypermethylated genes and fewer hypomethylated ones. The differentially methylated genes between better-parent F1 hybrids, the parents and lowerparent F1 hybrids were enriched in the categories metabolic processes, response to stress, binding, and catalytic activity, development, and involved in hormone biosynthesis, signaling pathway.
\end{abstract}

Conclusions: The methylation patterns of the parents both partially and dynamically passed onto their hybrids, and F1 hybrids has a non-additive mathylation level. A multidimensional process is involved in the formation of heterosis.

\section{Background}

Heterosis/hybrid vigor is the phenomenon in which progeny are superior to their parents (with distinct genetic backgrounds) in many traits, such as biomass, growth rate, adaptability, fertility, and resistance [1-5]. Since interspecific hybrid tobacco with hybrid vigor was produced in the 1760s by crossing Nicotiana rustuca with N. paniculata [6], heterosis has often been exploited in

\footnotetext{
* Correspondence: suxh@caf.ac.cn

† Contributed equally

'State Key Laboratory of Tree Genetics and Breeding, Research Institute of

Forestry, Chinese Academy of Forestry, 100091 Beijing, P.R. China

Full list of author information is available at the end of the article
}

crop and tree breeding. However, the genetic basis of heterosis is still far from being understood and is still a controversial subject $[1,7,8]$. Three classic hypotheses, i.e., dominance, overdominance, and epistasis, were proposed as genetic explanations for heterosis. In the dominance hypothesis, the inferior parental alleles in the hybrids are complemented by the superior or dominant alleles from the other parent. In the overdominance hypothesis, heterosis arises from allelic interactions within each of many genetic loci. An alternate model, epistasis, postulates that interactions between different parental genes in hybrids lead to heterosis. Although numerous examples support each of these hypotheses, 
they only partially explain the genetic basis of heterosis $[1,3,9]$.

Genome-wide analyses of heterosis have revealed altered gene expression profiles in F1 hybrids compared with their parents, as well as non-additive patterns of gene expression [2,10], including studies in maize (Zea mays L.) [11-14], rice (Oryza.sativa L.) [15,16], Arabidopsis thaliana [17], wheat (Triticum aestivum L.) [18], Larix kaempferi (Lamb.) Carr [19], and Populus tremula [20]. Recently, heterosis was observed in hybrids derived from parents with similar genetic backgrounds. Such parents with highly similar genomic features had distinct epigenomes [21-23], and epialleles that arise from epigenetic modification were also identified. Epi-alleles cause allelic variation and altered gene expression activity, which are essential to the architecture of plant heterosis [24]. One type of epigenetic regulation, DNA methylation, primarily serves as an epigenetic silencing mechanism and predominantly occurs in transposons and other repetitive DNA elements [5,25-29] and has been explored in model plants and crops, such as maize, rice, cotton (Gossypium herbaceum L.), and A. thaliana.

The genus Populus (poplar) includes species that are important for the health of ecosystems and are vital to the timber, paper, and biofuel industries. Poplars are also used as a model woody plant species and models of interest for epigenetic studies [30,31]. Variations in DNA methylation between genotypes and tissues and in response to drought, as well as the relationship between gene-body DNA methylation and tissue-specific gene expression, have been reported [31-34].

During the last century, many poplar varieties with enhanced growth or adaptability have been generated using inter- or intraspecific hybridization approaches, which take advantage of the presence of heterosis in poplars. Although investigations of the molecular basis of heterosis in poplar have been undertaken via genetic mapping and gene expression profiling, the global patterns of epigenetic modification such as DNA methylation have not been determined, and whether DNA methylation plays a role in the architecture of heterosis is still unclear. In this study, $P$. deltoides cl.'55/65' was maternal parent which has straight bole, round crown, fast growth, high resistance to Anoplophora glabripennis and strong rooting ability, and P. deltoides cl. '10/17' was paternal parent which fast-growth and high stress resistance. This crosscombination is multigeneration convergent cross. Intraspecific F1 hybrids of $P$. deltoides with significant hybrid vigor or lower-parental performance were examined. Methylated DNA immunoprecipitation, combined with a high-throughput sequencing (MeDIP-Seq) approach were applied to analyze the genome-wide DNA methylation landscapes in Populus deltoides parental lines and F1 hybrids lines. The results showed that better-parent F1 hybrids have higher methylation levels than the average of the parents, suggesting that non-additive level of DNA methylation is related to heterosis/hybrid vigor. The hypermethylated genes of better-parent F1 hybrids relative to the parents and lower-parent F1 hybrids were enriched in the processes of metabolism and development, which may be highly relevant to heterosis.

\section{Methods}

\section{Plant materials and growth conditions}

Two $P$. deltoides intraspecific parental lines, $P$. deltoides cl. '55/65' (Salicaceae, Populus, Section Aigeiros) and P. deltoides cl. '10/17' (Salicaceae, Populus, Section Aigeiros) and their intraspecific hybrids, designated here as $\mathrm{H}_{1}, \mathrm{H}_{2}, \mathrm{H}_{3}, \mathrm{~L}_{1}$ and $\mathrm{L}_{2}$, were used in this study. All F1 Hybrids was generated by the same intraspecific crosscombination of $P$. deltoides $\mathrm{cl}$. '55/65' as maternal parent and $P$. deltoides $\mathrm{cl}$. '10/17' as paternal parent. P. deltoides cl. '55/65' was primitively generated from the inbred seeds of excellent individual plants in former Yugoslavia and introduced into China in 1981. P. deltoides cl. '10/17' was generated by intraspecific crossing $P$. deltoides Bartr. cv. 'Shanhaiguanensis' (which was primitively generated from the inbred seeds of excellent individual plants and introduced into China in 1900) with P. deltoides Bartr. cl. 'Harvard' (I-63/51) (which was primitively generated from the inbred seeds of excellent individual plants in Mississippi Delta and introduced into China in 1972).

Hybrids were generated by hand pollination. All seeds were grown in a greenhouse at the Chinese Academy of Forestry (the authority responsible is the Chinese Academy of Forestry, Beijing, China) in January, 2002. Oneyear-old seedlings were made into cuttings to accelerate cloning, which were planted in the greenhouse in January, 2003 and transplanted to Yuquan mountain nursery (the authority responsible is the Chinese Academy of Forestry, Beijing, China) in May, 2003. No specific permits were required for these locations. The locations are not privately owned in any way, and the field studies did not involve endangered or protected species. A total of $149 \mathrm{~F} 1$ hybrids were introduced into Jiaozuo Research Institute of Forestry (Henan province, China) in 2003 and 2004. Of these, 18 F1 hybrids that had good performance in tree height and Diameter at breast height (DBH) were selected over the course of the two-year seedling test. Parents and their 18 F1 hybrids were planted in Xifeng village, Wuzhi Country, Jiaozuo city in Henan province in 2005 and then transplanted to Yangcheng, Wuzhi Country, Jiaozuo city of Henan province $\left(35^{\circ} 8^{\prime} \mathrm{N}, 113^{\circ} 17^{\prime} \mathrm{E}\right)$, in 2007 . No specific permits were required for these locations. The location is not privately owned in any way, and the field studies did not involve endangered or protected species. This site has an annual average precipitation of $625.4 \mathrm{~mm}$, with an annual average temperature of $15.2^{\circ} \mathrm{C}$ (ranging from $14.3^{\circ} \mathrm{C}$ to $43.6^{\circ} \mathrm{C}$ ), an accumulated temperature above $0^{\circ} \mathrm{C}$ 
of $4,633^{\circ} \mathrm{C}$, and a frostless period of 224 days per year. The average relative humidity and annual sunshine duration are $61 \%$ and 2,434 hours, respectively. The experimental field had an average soil $\mathrm{pH}$ of 6.8 and was irrigated. This trial was designed in randomized complete blocks, with four blocks and eight trees per treatment (planting spacing of $3 \mathrm{~m} \times 5 \mathrm{~m}$ ). After 5 years of growth, three F1 hybrids $\left(\mathrm{H}_{1}, \mathrm{H}_{2}\right.$, and $\left.\mathrm{H}_{3}\right)$ which exhibited the highest tree heights and largest DBHs and two $\mathrm{F}_{1}$ hybrids $\left(\mathrm{L}_{1}\right.$ and $\left.\mathrm{L}_{2}\right)$ that showed the lowest tree heights and DBHs were selected.

Since DNA methylation differences among tissues are obvious in Poplar [34] and leaves are important to plant growth and development, after five years of growth, the leaves at the top of main trunk were collected at the vigorous stage (9:30-10:30 am on August 10, 2011). Three trees (three leaves per tree) per replication were sampled, thus, twelve trees and 36 leaves were sampled for every line. Samples for every parent and F1 hybrid were pooled and stored in liquid nitrogen prior to DNA extraction.

\section{Evaluation of heterosis}

Since planting (in 2007), two important economic traits, tree height and DBH were continuously measured. Considering heterosis over higher parent was important for poplar breeding, after five years of growth, heterosis over higher parent was calculated as $\mathrm{H}=(\mathrm{F} 1-\mathrm{Ps}) / \mathrm{Ps} \times$ $100 \%$, where $\mathrm{H}$ is the amount of heterosis, F1 is the trait value measured in the hybrid, and Ps is the trait value measured in the higher parent [35].

\section{MeDIP-Seq}

Genomic DNA was isolated from each sample using a DNeasy Plant Mini Kit (Qiagen, Courtaboeuf, France). The DNA integrity was verified by agarose gel electrophoresis. The DNA was quantified using a Qubit Fluorometer and a Quant-iT ${ }^{\mathrm{TM}}$ dsDNA BRAssay Kit (Life Technologies, USA).

The MeDIP process was almost identical to the method of Pomraning et al [36]. Before carrying out MeDIP, genomic DNA was sheared to 350-450 bp fragments with a Bioruptor (Sonics, Newtown, USA, VC130PB), and the fragments were recovered using a Qiaquick PCR Purification Kit (Qiagen, Courtaboeuf, France). The fragments were end-repaired, phosphorylated, and A-tailed. The fragments were then ligated to Illumina sequencing adapters [37]. The sheared DNA was diluted in $450 \mu \mathrm{l}$ of TE buffer, denatured in a $100^{\circ} \mathrm{C}$ heat block for $10 \mathrm{~min}$, and snapcooled on ice for $5 \mathrm{~min}$. Immunoprecipitation buffer (100 mM Na-Phosphate pH 7.0, 1.4 M NaCl, 0.5\% TritonX-100) and $1 \mu \mathrm{l}$ of $5 \mathrm{meC}$ antibody (Diagenode, Liège, Belgium \#MAb-5MECYT-100, $1 \mu \mathrm{g} / \mu \mathrm{l}$ ) were added to the DNA solution followed by incubation for $2 \mathrm{~h}$ on an orbital rotator at $4^{\circ} \mathrm{C}$. Bound DNA was precipitated with sheep anti-mouse IgG Dynabeads (M-280, Invitrogen, California, USA), washed three times with immunoprecipitation buffer for $10 \mathrm{~min}$ at room temperature with shaking, resuspended in $250 \mu \mathrm{l}$ proteinase $\mathrm{K}$ digestion buffer $(5 \mathrm{mM}$ Tris, pH 8.0, 1 mM EDTA, pH 8.0, 0.05\% SDS) with $7 \mu \mathrm{l}$ of $10 \mathrm{mg} / \mathrm{ml}$ proteinase $\mathrm{K}$, and incubated for $3 \mathrm{~h}$ on an end-over-end rotator at $50^{\circ} \mathrm{C}$ to digest the antibodies and release the $5 \mathrm{meC}$-containing DNA. Methylated DNA was extracted by phenol-chloroform extraction followed by ethanol precipitation. The DNA pellets were resuspended in $50 \mu \mathrm{l} \mathrm{TE}$ buffer and stored at $-20^{\circ} \mathrm{C}$.

The immunoprecipitated DNA was used to generate a DNA colony template library using the Fasteris procedure (Fasteris, Plan-les-Ouates, Switzerland). The DNA samples were quantified using a 2100 Bioanalyzer (Agilent, USA) and a StepOnePlus Real-Time PCR System (ABI, California,USA). Illumina sequencing was performed in a HiSeq-2000 system (Illumina, San Diego, CA, USA).

\section{Bioinformatics processing and statistical analysis}

MeDIP-Seq reads were aligned to the Populus trichocarpa v2.2 reference genome (http://www.phytozome.net/poplar. php, February 2012). The alignments were carried out with SOAP aligner (BGI, version 2.01) [38], allowing up to two mismatches for successful mapping. The mapped rate (the ratio of the number of mapped reads to that of original reads), and the uniquely mapped rate (the ratio of the number of uniquely mapped reads to that of original reads) were calculated. The coverage depth was calculated as the coverage times of specific loci by sequencing reads. The genome coverage was calculated as the proportion of eligible base numbers in the entire genome. In the distribution analysis of the MeDIP-Seq sequencing reads in a chromosome, each chromosome was scanned with windows of $100 \mathrm{~kb}$, the reads coverage depth per window was calculated, and the reads were standardized with the following formula: reads number of specific $100 \mathrm{~kb}$ windows * 1,000,000/number of uniquely mapped reads. The methylation coverage of $\mathrm{CG} / \mathrm{CHG} / \mathrm{CHH}$ contexts was calculated as the proportion of $\mathrm{CG} / \mathrm{CHG} / \mathrm{CHH}$ site over certain coverage depth in all $\mathrm{CG} / \mathrm{CHG} / \mathrm{CHH}$ sites from as determined by MeDIP-Seq.

Peak summit coordinates were generated using modelbased analysis of ChIP-Seq (MACS; version 1.4.0 beta) [39]. The summit files were then used for further analysis (total peaks number, peak mean length, peak median length, peak total length, and peak covered size in the genome).

To detect differentially methylated gene between the two samples, the peak summits of two samples were merged, and the normalized reads number of each sample the merged region was determined. The false positive reads were removed using a chi-square test. For genes 
that overlapped with a merged region, if the reads number of sample 2 in this region was more than that of sample 1 , then the gene was designated as hypermethylated during the Sample 1 versus Sample 2 comparison, while if the opposite situation occurred, the gene was considered to be hypomethylated.

Gene Ontology (GO) analysis was performed to obtain the functional classifications of differentially methylated genes using the TermFinder tool (http://search.cpan.org/ $\sim$ sherlock/GO-TermFinder-0.86/). P-values were multiple test corrected to reduce false positive rates. GO terms with adjusted P-values of $<0.05$ were considered to be significant.

The known genes were submitted to the KEGG Automatic Annotation Server (http://www.genome.jp/kegg/ pathway.html) for pathway analysis. A hypergeometric test was performed to identify the significantly enriched pathways in differentially methylated genes compared with the whole genome. Pathways with Q-values $\leq 0.05$ were considered to be significant.

\section{Results}

\section{Heterosis performance}

Analysis of Variance (ANOVA) of the height and DBH of trees of various ages (from one to five years old) for the parents and F1 hybrids was performed. The results showed that the tree height and DBH in each age of parents and F1 hybrids were significantly different (Figure 1, Additional file 1: Table S1). The tree heights and DBHs of $\mathrm{H}_{1}, \mathrm{H}_{2}$, and $\mathrm{H}_{3}$ at each age were higher than those of the parents (except for the annual tree height of $\mathrm{H}_{2}$ ). The tree heights of $\mathrm{H}_{1}, \mathrm{H}_{2}$, and $\mathrm{H}_{3}$ at five-year were significantly greater than those of the parents. The tree heights of $\mathrm{L}_{1}$ and $\mathrm{L}_{2}$ at five-year were lower than those of the parents, and the $\mathrm{DBH}$ of $\mathrm{L}_{1}$ and $\mathrm{L}_{2}$ at five-year were both significantly lower than those of the parents. Since heterosis over higher parent is important for poplar breeding, we estimated the heterosis over higher parent values (Table 1). Hybrids $\mathrm{H}_{1}, \mathrm{H}_{2}$, and $\mathrm{H}_{3}$ exhibited heterosis over higher parent for tree height $\left(7.81 \%\right.$ for $\mathrm{H}_{1}, 12.55 \%$ for $\mathrm{H}_{2}$, and $11.09 \%$ for $\left.\mathrm{H}_{3}\right)$ and $\mathrm{DBH}\left(1.26 \%\right.$ for $\mathrm{H}_{1}$, $1.49 \%$ for $\mathrm{H}_{2}$, and $0.72 \%$ for $\mathrm{H}_{3}$ ), while hybrids $\mathrm{L}_{1}$ and $\mathrm{L}_{2}$ possessed negative heterosis over higher parent for tree height $\left(-5.77 \%\right.$ for $\mathrm{L}_{1}$ and $-7.59 \%$ for $\left.\mathrm{L}_{2}\right)$ and $\mathrm{DBH}$ $\left(-20.92 \%\right.$ for $L_{1}$ and $-21.82 \%$ for $\left.L_{2}\right)$.

\section{Mapping of MeDIP-Seq reads to the reference genome} MeDIP-Seq libraries were constructed from DNA extracted from the parents and their hybrids and subjected to high-throughput Solexa sequencing (Illumina, San Diego, CA, USA). A total of 670 million reads were produced from the $\mathrm{P}_{1}, \mathrm{P}_{2}, \mathrm{H}_{1}, \mathrm{H}_{2}, \mathrm{H}_{3}, \mathrm{~L}_{1}$, and $\mathrm{L}_{2}$ lines. The reads were mapped to the $P$. trichocarpa v2.2 reference genome (http://www.phytozome.net/poplar.php).
A total of 486.27 million reads could be mapped in this process. The mapped rates for the seven lines were $83.4 \%, 74.2 \%, 82.4 \%, 65.1 \%, 65.9 \%, 63.5 \%$, and $71.7 \%$, respectively (average of $72.31 \%$ ). The uniquely mapped rates were $66.4 \%, 56.8 \%, 65.6 \%, 55.3 \%, 52.0 \%, 53.0 \%$, and $55.6 \%$, respectively (average of $57.8 \%$; Table 2 ). To facilitate the access and use of the $P$. deltoides methylome sequencing data, the raw data in the FASTQ format was deposited in the National Center for Biotechnology Information (NCBI) Sequence Read Archive (SRA) database with accession number SRP034728.

\section{Comparison of methylation status among parents and F1 hybrid genomes}

In this study, the leaf methylomes of the parents and F1 hybrids were investigated. The distribution of MeDIP-Seq reads on the 19 scaffolds (each scaffold represents a putative chromosome) of Populus was shown in Figure 2. Distinct DNA methylomes were observed among the parents and F1 hybrids. Among the 19 chromosomes, nine (I, IV, VI, VII, XI, XII, XVI, XVIII, and XIX) had greater methylation coverage in the middle parts of chromosomes, which may comprise the centromeric regions [34]. Moreover, three chromosomes (II, VIII, and XIII) had greater methylation coverage in distal parts of the chromosomes, while four (III, IX, X, and XV) had greater methylation coverage in proximal parts of the chromosomes.

Different types of methylation coverage were also observed in the parents and F1 hybrids (Figure 3). In plant, DNA methylation in often found in all sequence, namely, the symmetric $\mathrm{CG}$ and $\mathrm{CHG}$ contexts ( $\mathrm{H}$ represents $\mathrm{A}, \mathrm{T}$, and $\mathrm{C}$ ) and asymmetric $\mathrm{CHH}$ contexts [40]. We calculated the methylation coverage of CG/CHG/ $\mathrm{CHH}$ contexts. We found that remarkable methylation occurred in each cytosine context in the genomes of parents and F1 hybrids. Moreover, the methylation coverage in $\mathrm{CG}, \mathrm{CHH}$, and $\mathrm{CHG}$ displayed clear differences between parents $P_{1}$ and $P_{2}$. The methylation coverage in the three sequence contexts for maternal parent $\mathrm{P}_{1}$ was $17.24 \%, 19.24 \%$, and $18.83 \%$, respectively, while that for paternal parent $\mathrm{P}_{2}$ was $12.61 \%, 13.35 \%$, and $12.92 \%$, respectively (Figure 3). For better-parent hybrids, the methylation coverage of $\mathrm{H}_{1}$ was $16.97 \%$ (CG), $18.79 \%$ (CHG), and $18.44 \%(\mathrm{CHH})$, respectively. $\mathrm{H}_{2}$ and $\mathrm{H}_{3}$ had comparable values to $\mathrm{H}_{1}$, with an average of $16.06 \%$, $17.40 \%$, and $17.33 \%$ for $\mathrm{CG}, \mathrm{CHG}$, and $\mathrm{CHH}$ contexts, respectively (Figure 3 ). These results indicate that the methylation levels of all better-parent hybrids were between those of the two parents (less than $\mathrm{P}_{1}$ and more than $\mathrm{P}_{2}$ ), while the values were higher than the average levels of the parents $(14.94 \%, 16.31 \%$, and $15.88 \%$, respectively). For lower-parent hybrids, $\mathrm{L}_{2}$ displayed an average methylation coverage of $16.35 \%$ for the three contexts, which was less than that of $\mathrm{P}_{1}$ but 


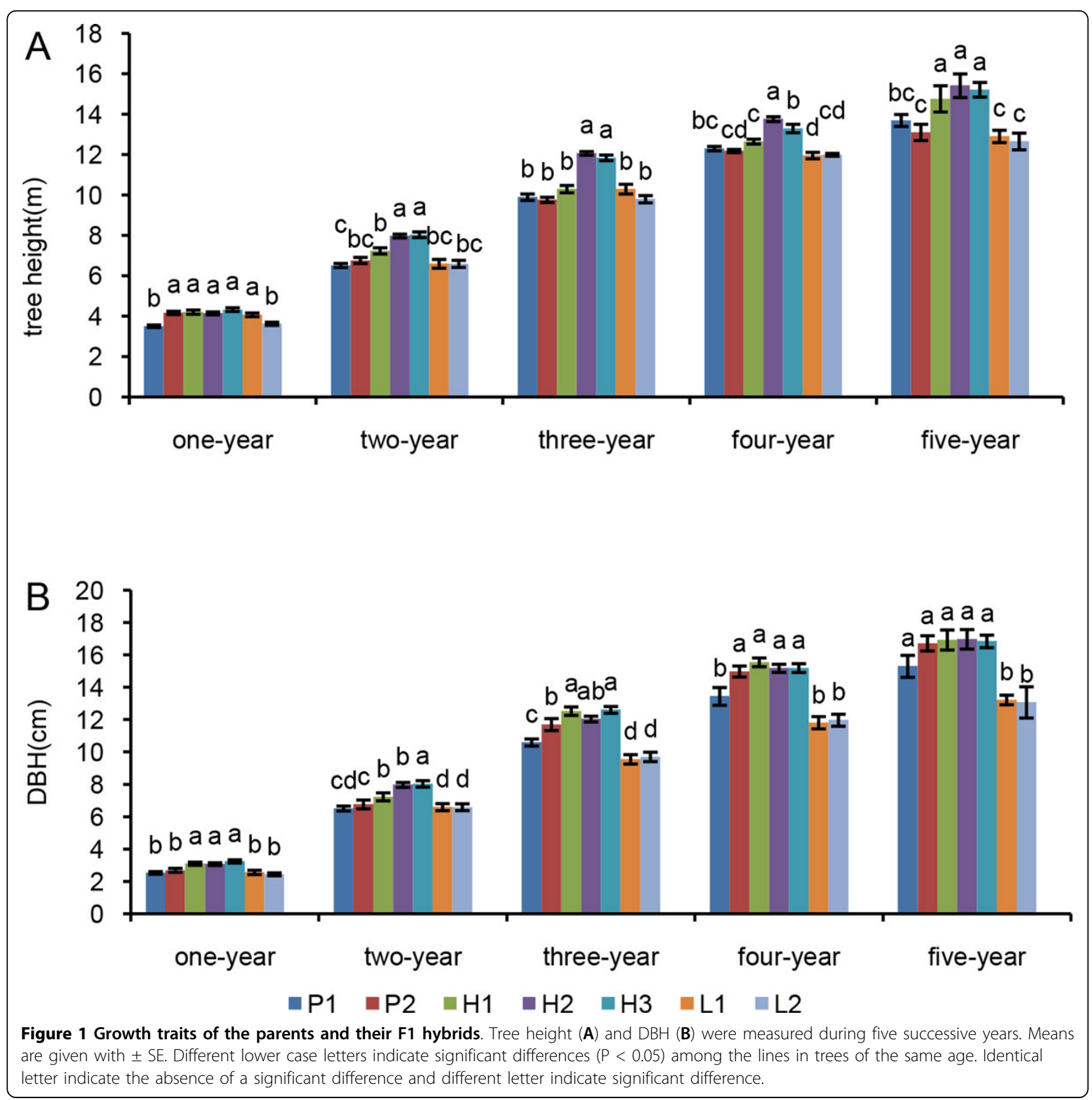

Table 1 Heterosis of F1 hybrids

\begin{tabular}{cccc}
\hline Clone No. & Age (year) & \multicolumn{2}{c}{ heterosis over better parent \% } \\
\hline & & Tree height & DBH \\
\hline$H_{1}$ & 5 & $7.81 \pm 0.05$ & $1.26 \pm 0.03$ \\
$H_{2}$ & 5 & $12.55 \pm 0.06$ & $1.49 \pm 0.02$ \\
$H_{3}$ & 5 & $11.09 \pm 0.04$ & $0.72 \pm 0.01$ \\
$L_{1}$ & 5 & $-5.77 \pm 0.03$ & $-20.92 \pm 0.03$ \\
$L_{2}$ & 5 & $-7.59 \pm 0.05$ & $-21.82 \pm 0.05$ \\
\hline
\end{tabular}

Heterosis over higher parent was calculated as $\mathrm{H}=(\mathrm{F} 1-\mathrm{Ps}) / \mathrm{Ps} \times 100 \%$, where $\mathrm{H}$ is the amount of heterosis, F1 is the trait value of the hybrid, and Ps is the trait value of the better parent. more than that of $\mathrm{P}_{2}$, while the values of $\mathrm{L}_{1}$ were $10.21 \%, 10.21 \%$, and $10.05 \%$, respectively, which were less than those of both parents (Figure 3).

\section{Mapping of MeDIP-Seq reads to genes}

The distribution of MeDIP-Seq reads on various genomic features, including $\mathrm{CpG}$ islands, promoters, 5' untranslated regions (UTRs), 3 ' UTRs, coding sequences (CDS), and introns, was characterized based on methylation coverage. Promoters are defined as the $2-\mathrm{kb}$ region upstream of the annotated transcription start site. 
Table 2 Summary of MeDIP-Seq experimental results

\begin{tabular}{|c|c|c|c|c|c|c|c|c|}
\hline $\begin{array}{l}\text { line } \\
\text { No. }\end{array}$ & $\begin{array}{l}\text { length of sequence } \\
\text { reads (bp) }\end{array}$ & $\begin{array}{l}\text { Total } \\
\text { reads }\end{array}$ & $\begin{array}{c}\text { No. } \\
\text { mapped } \\
\text { reads }^{\text {a }}\end{array}$ & $\begin{array}{l}\text { Percent } \\
\text { mapped } \\
\text { read (\%) }\end{array}$ & $\begin{array}{c}\text { No. } \\
\text { mapped } \\
\text { base }\end{array}$ & $\begin{array}{c}\text { No. unique } \\
\text { mapped } \\
\text { reads } b\end{array}$ & $\begin{array}{c}\text { No. unique } \\
\text { mapped } \\
\text { base }\end{array}$ & $\begin{array}{c}\text { Percent unique mapped } \\
\text { read (\%) }\end{array}$ \\
\hline$P_{1}$ & 49 & $97,959,184$ & $81,729,006$ & 83.4 & $4,004,721,294$ & $65,078,019$ & $3,188,822,931$ & 66.4 \\
\hline$P_{2}$ & 49 & $97,959,184$ & $72,679,485$ & 74.2 & $3,561,294,765$ & $55,648,568$ & $2,726,779,832$ & 56.8 \\
\hline $\mathrm{H}_{1}$ & 49 & $97,959,184$ & $80,814,131$ & 82.4 & $3,959,892,419$ & $64,231,654$ & $3,147,351,046$ & 65.6 \\
\hline $\mathrm{H}_{2}$ & 49 & $97,959,184$ & $63,730,201$ & 65.1 & $3,122,779,849$ & $54,140,276$ & $2,652,873,524$ & 55.3 \\
\hline $\mathrm{H}_{3}$ & 49 & $97,959,184$ & $64,510,366$ & 65.9 & $3,161,007,934$ & $50,943,321$ & $2,496,222,729$ & 52.0 \\
\hline$L_{1}$ & 49 & $82,792,658$ & $52,534,101$ & 63.5 & $2,574,170,949$ & $438,630,69$ & $2,149,290,381$ & 53.0 \\
\hline $\mathrm{L}_{2}$ & 49 & $97,959,184$ & $70,275,601$ & 71.7 & $3,443,504,449$ & $54,474,434$ & $2,669,247,266$ & 55.6 \\
\hline Total & & $670,547,762$ & $486,272,891$ & & & & & \\
\hline
\end{tabular}

The sequencing reads were mapped to the Populus trichocarpa v2.2 reference genome (http://www.phytozome.net/poplar.php), allowing for up to two mismatches per read. (a) the mapped reads indicate the reads mapped to the reference genome. (b) the uniquely mapped reads indicate the reads number mapped to the unique loci in the reference genome.

Methylation coverage in promoters of the parents and F1 hybrid was higher than that of the gene body (Figure 4). Moreover, CDS and introns of the gene body had higher methylation coverage, while the 5'-and 3'- UTRs had very low methylation coverage. We also compared the methylation coverage on various genomic features among parents, better-parent F1 hybrids, and lower-parent F1 hybrids. We found that three better-parent F1 hybrids had higher methylation coverage in promoters, 5 'UTRs and 3' UTRs than those of the parents and the lower-parent hybrids. In intron, the methylation coverage of $\mathrm{H}_{2}$ was higher than other lines, the coverage of $\mathrm{P}_{1}, \mathrm{H}_{1}, \mathrm{H}_{3}$ and $L_{2}$ were similar, the coverage of $\mathrm{P}_{2}$ and $\mathrm{L}_{1}$ were similar (Figure 4, Additional file 2: Figure $\mathrm{S} 1$ ). $\mathrm{H}_{2}$ had higher methylation coverage in CDS, whereas the coverage of $\mathrm{L}_{2}$ was higher than $\mathrm{H}_{1}$ and $\mathrm{H}_{3}$ and the parents.

CpG islands (CGI) are a prime target for epigenetic modification. Moreover, $\mathrm{CpG}$ islands are more frequently found in plant genomes than in the human genome [41]. CGIs were previously thought to be unmethylated unless they were located at genomic imprinting sites or on the inactivated $\times$ chromosome [26]. Recent studies have shown that some CpG islands are methylated $[42,43]$. To further observe the distribution trend of DNA methylation in CGIs of Populus, 2,000-bp regions upstream and downstream of CGI were divided into 20 segments, and the CGI was divided into 40 segments. By counting the normalized average coverage depth, we determined that the CGIs in the parents and hybrids had methylation. $\mathrm{H}_{2}$ had the highest level of CGI methylation, followed by the lower-parent hybrids $\mathrm{L}_{1}$ and $\mathrm{L}_{2}$, the paternal parent $\mathrm{P}_{2}$, $\mathrm{H}_{1}$ and $\mathrm{H}_{3}$, and the maternal parent $\mathrm{P}_{1}$ (Figure 5).

Transposable elements and repetitive sequences are frequently methylated regions. Previous reports have suggested that inferring the methylation status in transposons and repetitive sequences at the whole-genome level using classic approaches, especially microarray- and PCR-based assays, is unreliable. This problem can be overcome by using the recently available MeDIP-Seq approach, which can be used to deduce the coverage of all major types of methylation for transposons and repetitive sequences [44]. In plants, numerous LTR-gypsy retrotransposon elements are present in the heterochromatic centromeric and pericentromeric regions. LTR-gypsy retrotransposon elements are the most abundant type of transposon element in the Populus trichocarpa genome [45]. We detected the enrichment of LTR-gypsy retrotransposons in the DNAmethylated fraction of the genomes of the parents and F1 hybrids. In addition, genome regions containing LTR copia, DNA/En-Spm, Low-complexity (which contains a highly non-uniform amino acid composition [46,47]), and Simple-repeat were also methylated (Figure 6). The variations in methylation in transposable elements and repetitive sequences seem dependent on each genotype. The methylation coverages of the F1 hybrids were between those of the two parents in LTR-Gypsy, simple-repeat and Low_complexity (except for $\mathrm{L}_{2}$ in LTR-Gypsy). In LTRCopia, $\mathrm{H}_{1}, \mathrm{H}_{3}$ and $\mathrm{L}_{2}$ had higher methylation coverage with $\mathrm{H}_{2}$ and $\mathrm{L}_{1}$ had lower methylation coverage. In contrary, in rRNA and DNA/En-Spm, $\mathrm{H}_{2}$ and $\mathrm{L}_{1}$ had higher methylation coverage, whereas the methylation coverage of $\mathrm{H}_{1}$ and $\mathrm{H}_{3}$ were lower.

\section{Methylated peaks analysis}

To avoid the false positive results generated from MeDIP-Seq, model-based analysis of ChIP-Seq (MACS) was used to obtain methylation peak summits. In this analysis, the total number of peaks of the better-parent hybrids was higher than that of the parents, while that of the lower-parent hybrids was lower than that of the parents. The parents had distinct DNA methylation peak coverage. The number of peak coverage of the better-parent hybrid $\mathrm{H}_{1}$ was more than that of the parents, and those of the other two better-parent hybrids $\left(\mathrm{H}_{2}\right.$ and $\mathrm{H}_{3}$ ) were higher than the average levels of the parents. Moreover, the number of peak coverages of both 


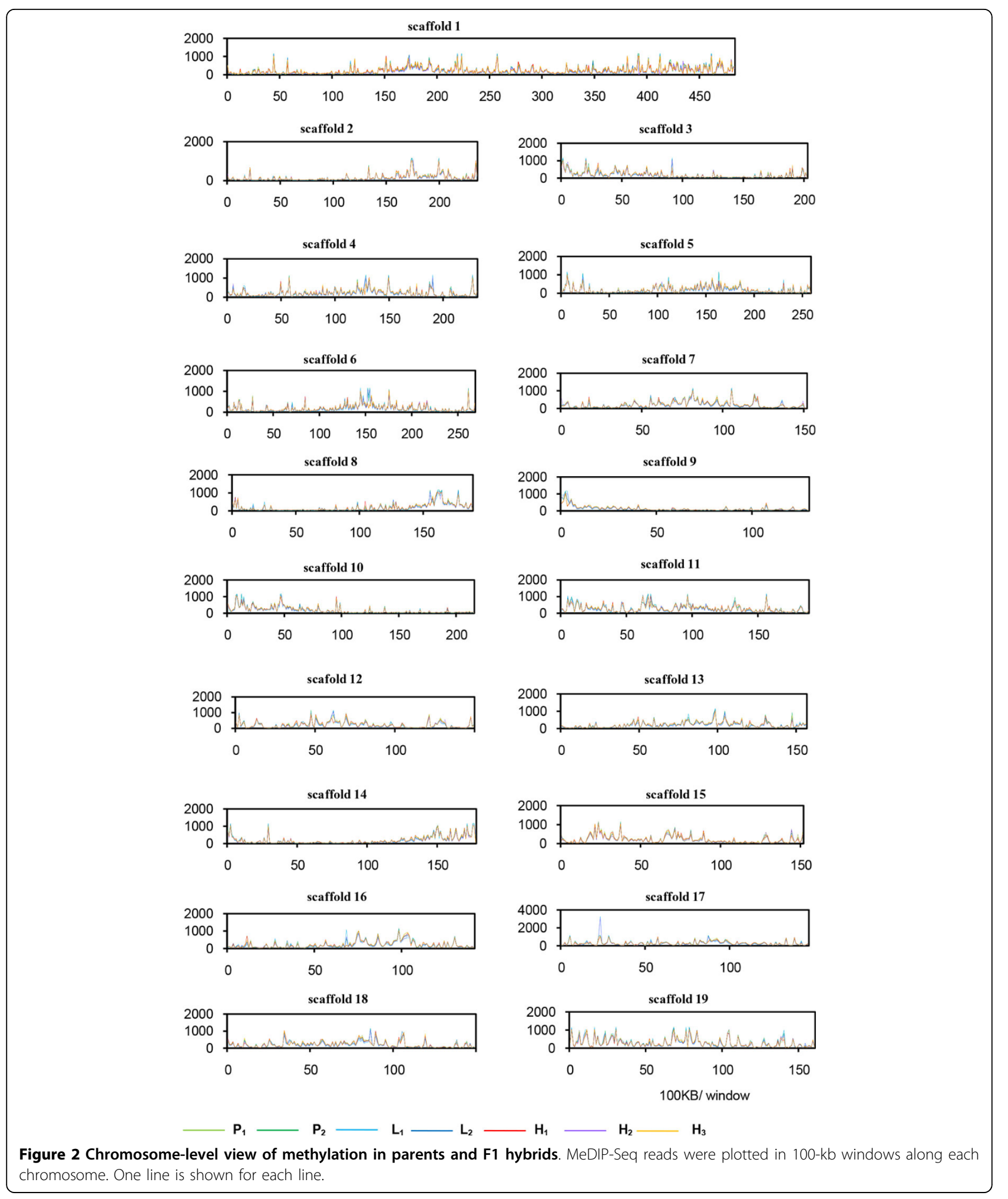

lower-parent hybrids was lower than those of the low parents (Table 3).

We further mapped peaks to various genomic features. Table 4 shows the peak number contained in each genomic feature. The peak number in the promoter regions was greater than that of the gene body. In the gene body, CDS had a higher peak number than introns and UTRs. The peak numbers in the promoter, 5'UTR, 


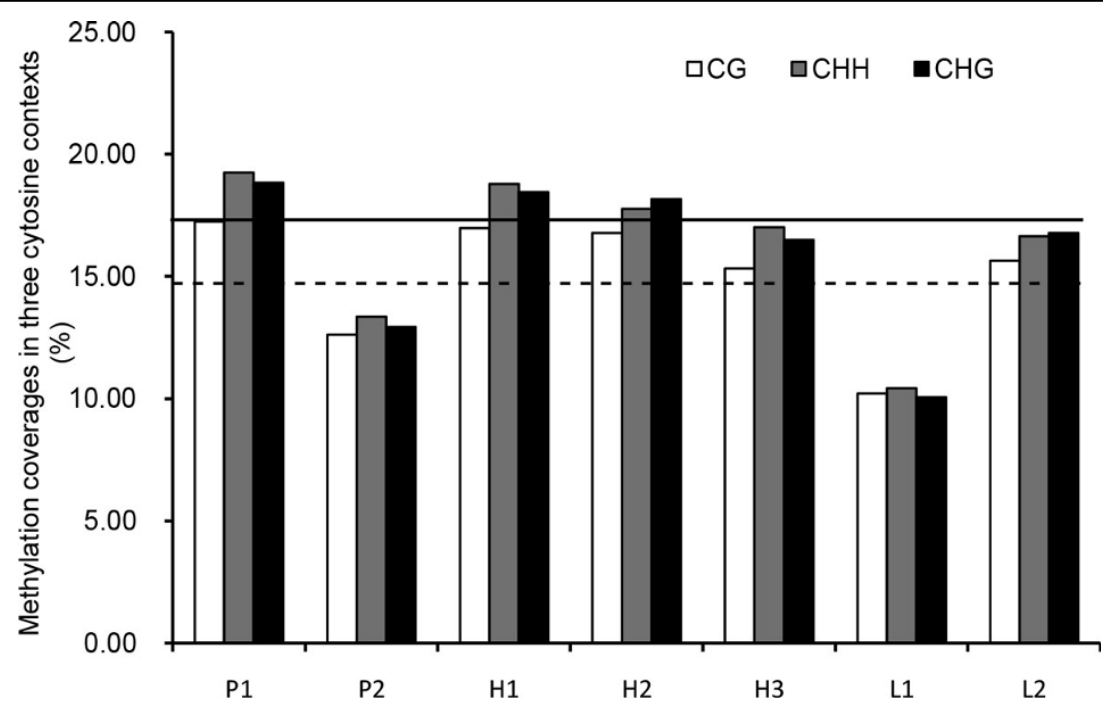

Figure 3 Comparison of DNA methylationin F1 hybrids relative to their parents. Each column indicates the proportion of the number of $\mathrm{CG} / \mathrm{CHG} / \mathrm{CHH}$ context over $1 \mathrm{X}$ sequence depth to all number of $\mathrm{CG} / \mathrm{CHG} / \mathrm{CHH}$ contexts. Black line indicates thepercentage of $\mathrm{CG}$ contexts in better parent, and black dotted line indicates the average of percentag of CG contexts in two parents.

and 3'UTR of better-parent hybrid F1 plants were higher than those of the parents. In introns, the peak number of $\mathrm{L}_{1}$ was higher than that of the other lines, while the peak numbers of $\mathrm{P}_{1}, \mathrm{H}_{1}$, and $\mathrm{H}_{2}$ were similar, and the peak numbers of $\mathrm{P}_{2}, \mathrm{H}_{3}$, and $\mathrm{L}_{2}$ were also similar.

Analysis of differentially methylated genes in the parental and $\mathrm{F} 1$ hybrid genomes

The number of differentially methylated gene among the parents and F1 hybrids is shown in Figure 7. Better- parent hybrid $\mathrm{H}_{1}$ had a similar number of hyper- and hypomethylated genes as the maternal parent $\mathrm{P}_{1}$ (589 and 580, respectively). By contrast, remarkably fewer genes with hypermethylated were detected relative to hypomethylated genes in better-parent hybrid $\mathrm{H}_{2}(1,338$ versus 4,189 genes) and $\mathrm{H}_{3}$ (414 versus 1,046 genes). Compared with the paternal parent $\mathrm{P}_{2}$, the better-parent hybrids displayed higher levels of hypermethylation at protein-coding genes, as more hypermethylated than hypomethylated genes were found in $\mathrm{H}_{1}(2,887$ versus

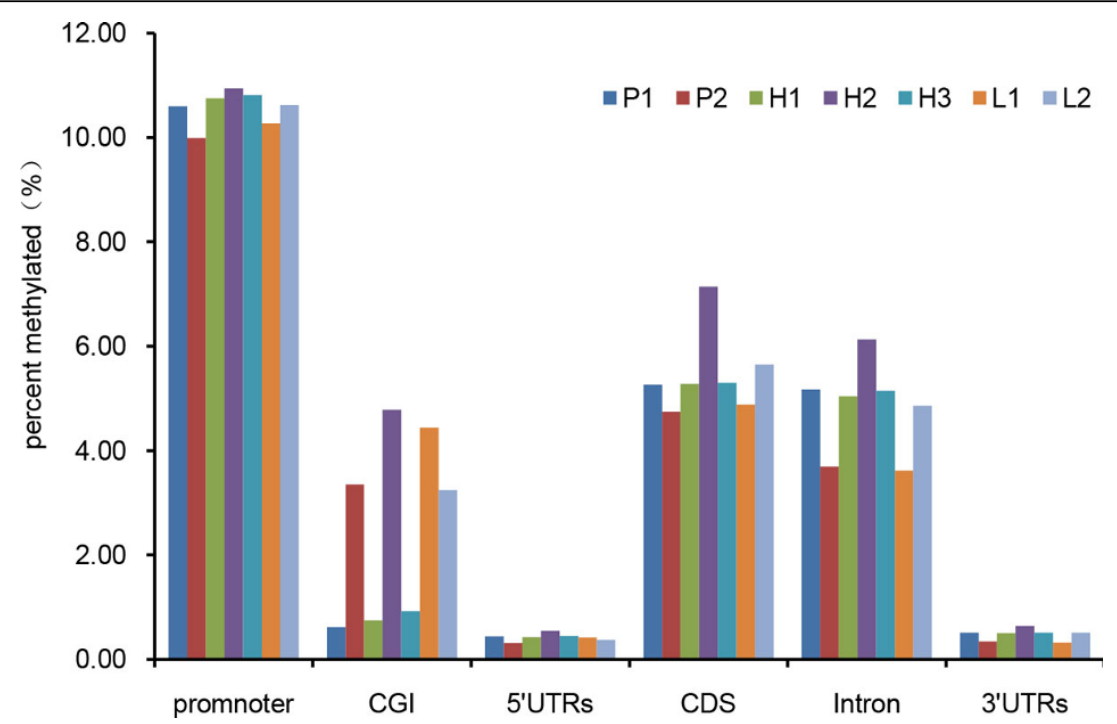

Figure 4 Fraction of methylation of genome features between parents and hybrids. Each column indicates the proportion of reads distributed in specific genome features of the total mapped reads. Promoters are defined as the 2-kb region upstream of the annotated transcription start site. CGI was determained by CpGPlot (http://www.ebi.ac.uk/Tools/seqstats/emboss_cpgplot/help/index.html). 


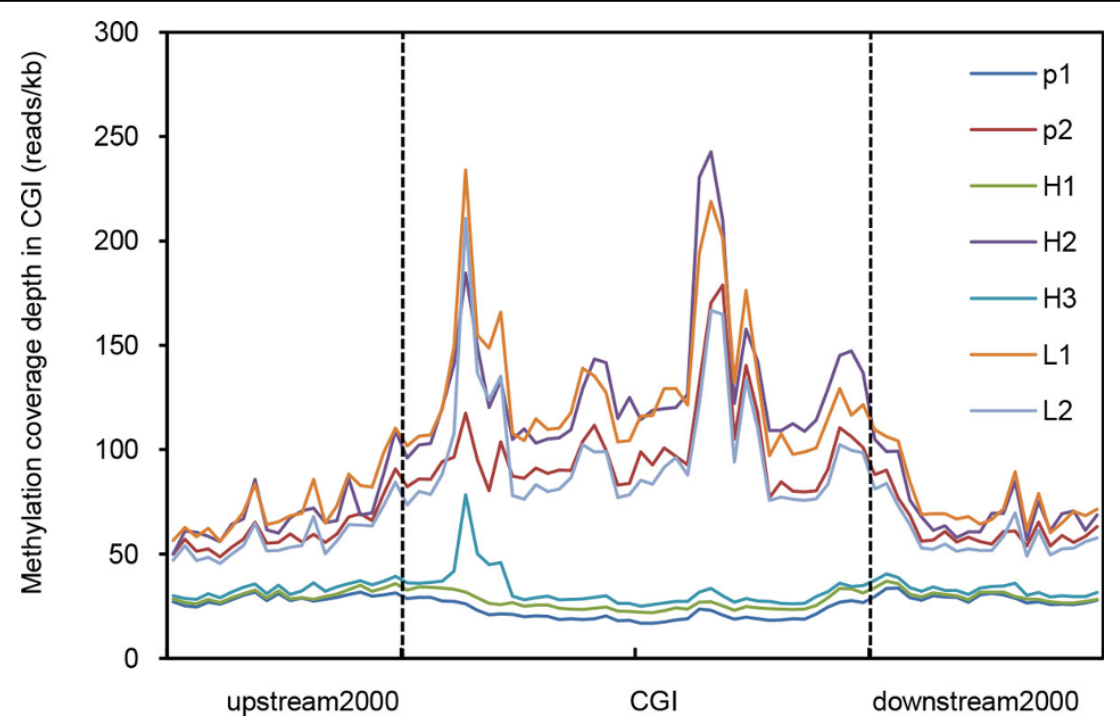

Figure 5 The trend of average coverage depth of DNA methylation in CGI. The region within the dotted line indicates CGI region.

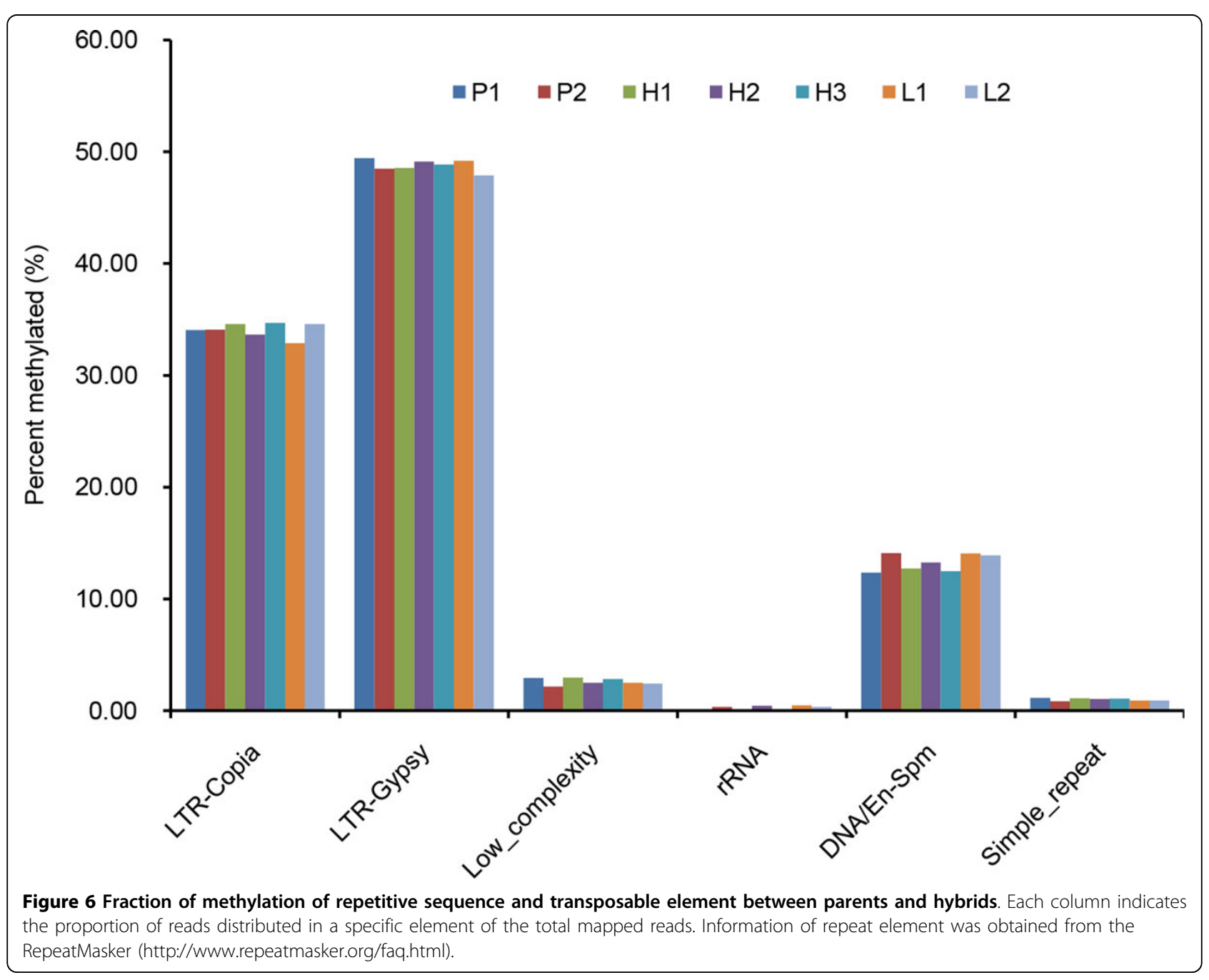


Table 3 Statistics of peak summits

\begin{tabular}{ccccc}
\hline Clone No. & Total peaks & Peak mean length /bp & $\begin{array}{c}\text { Peak total } \\
\text { length /bp }\end{array}$ & $\begin{array}{c}\text { Peak coverage in genome } \\
\text { (\%) }\end{array}$ \\
\hline $\mathrm{P}_{1}$ & 21,355 & 1697.33 & $36,246,472$ & 8.69 \\
$\mathrm{P}_{2}$ & 18,754 & 1791.66 & $33,600,816$ & 8.06 \\
$\mathrm{H}_{1}$ & 22,932 & 1617.75 & $37,098,304$ & 8.89 \\
$\mathrm{H}_{2}$ & 24,114 & 1418.43 & $34,203,905$ & 8.20 \\
$\mathrm{H}_{3}$ & 21,582 & 1633.20 & $35,247,816$ & 8.45 \\
$\mathrm{~L}_{1}$ & 18,699 & 1705.54 & $31,891,918$ & 7.65 \\
$\mathrm{~L}_{2}$ & 17,711 & 1861.72 & $32,972,998$ & 7.90 \\
\hline
\end{tabular}

Peak summits were generated using Model-based analysis of ChIP-Seq (MACS; version 1.4.0 beta).

Table 4 Number of peaks in genome features

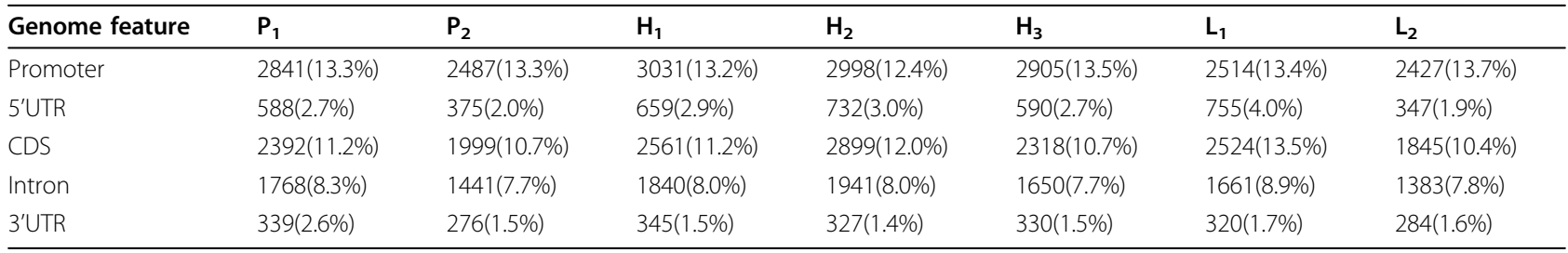

Number of peaks in Promoter, 5'UTR, CDS, Intron and $3^{\prime} U T R$ were calculated. The percentage indicates the ratio of the number of peaks in each feature to total peaks.

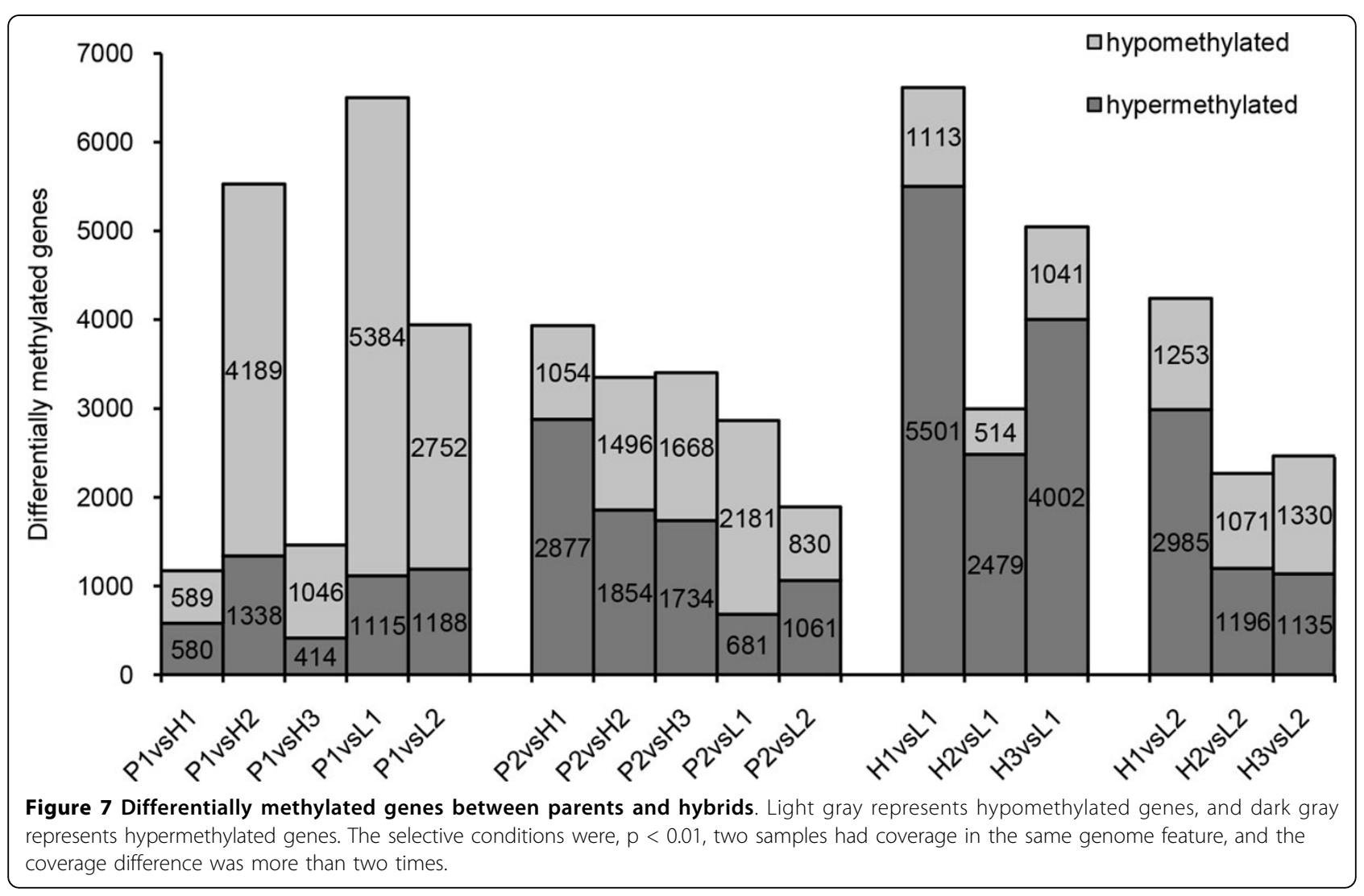


1,054 genes), $H_{2}$ (1,854 versus 1,496 genes), and $H_{3}$ (1,734 versus 1,668 genes). However, there were less hypermethylated than hypomethylated genes in hybrid $\mathrm{L}_{1}$ (681 versus 2,181 genes). When better-parent and lower-parent F1 hybrids were compared, we found higher levels of methylation in the better-parent hybrids than in $\mathrm{L}_{1}$, as inferred by the larger number of hypermethylated genes than hypomethylated genes in $\mathrm{H}_{1}$ (5,551 versus 1,113 genes), $\mathrm{H}_{2}$ (2,479 versus 514 genes), and $\mathrm{H}_{3}$ (4,002 versus 1,041 genes). Compared with $\mathrm{L}_{2}$, more genes with hypermethylation than hypomethylated genes were detected in $\mathrm{H}_{1}$ (2,985 versus 1,253 genes) and $H_{2}$ (1,196 versus 1,071 genes), whereas $H_{3}$ showed higher levels of methylation, with a greater number of hypomethylated genes (1,135 hypermethylated versus 1,330 hypomethylated).

For all of the differentially methylated genes identified, we performed Gene Ontology (GO) functional category analysis to determine whether these genes were enriched for certain pathway or network (Additional file 2: Figure S2). The results showed that the differentially methylated genes between better-parent hybrid $\mathrm{H}_{1}$ and maternal parent $\mathrm{P}_{1}$ were enriched in 28 biological functional categories, and ten additional enriched functional categories (biological adhesion, cell proliferation, locomotion, reproductive process, extracellular region, extracellular region part, enzyme regulator activity, molecular transducer activity, protein binding, and transcription factor activity) were also found for genes identified in the $\mathrm{H}_{1}-\mathrm{P}_{2}$ comparison. Compared with maternal parent $P_{1}$, better-parent hybrid $H_{2}$ possessed more hypermethylated genes enriched in 35 functional categories, such as biological adhesion, cell proliferation, protein binding, and transcription factor activity. The differentially methylated genes between $\mathrm{H}_{2}$ and paternal parent $\mathrm{P}_{2}$ were enriched in 33 functional categories (e.g., pigmentation). The differentially methylated genes between better-parent hybrid $\mathrm{H}_{3}$ and maternal parent $\mathrm{P}_{1}$ were enriched in 31 functional categories, and two additional categories (cell proliferation and molecular transducer activity) were found to have enriched differentially methylated genes between $\mathrm{H}_{3}$ and $\mathrm{P}_{2}$. As a whole, the majority of hypermethylated genes between three better-parent hybrids and both parents tended to fall into seven functional categories, including metabolic processes, cellular, response to stress, cell, cell part, binding, and catalytic activity.

To further investigate the differentially methylated genes between better-parent F1 hybrids and the parents, we analyzed hypermethylated genes enriched in specific functional categories in $\mathrm{H}_{1}, \mathrm{H}_{2}$, and $\mathrm{H}_{3}$ versus the two parents (Figure 8A). 20 and 199 genes showed hypermethylation in all three better-parent $F_{1}$ hybrids compared with $P_{1}$ and $\mathrm{P}_{2}$, respectively. Among these genes, 97 fell into seven major GO functional categories, namely metabolic process (31), cellular metabolic process (21), primary metabolic process (17), small molecule metabolic process (10), nitrogen compound metabolic process (7), developmental process (6), and anatomical structure development (5). Notably, four genes (POPTR_0008s18650, POPTR_ 0010s02290, POPTR_0017s03190, and POPTR 0010s19920) with hypermethylation were detected in all better-parent hybrid-parent comparisons (Table 5). Among these, POPTR_0010s02290 encodes a predicted GTP-binding protein with GTPase activity and protein binding functions, and POPTR_0010s19920 encodes 3dehydrosphinganine reductase, which participates in metabolic processes and oxido-reductase activity. The genes were submitted to the KEGG Pathway (http://www.genome.jp/kegg/pathway.html) database to obtain their KEGG orthology annotations. POPTR_0010s19920 was found to participate in sphingolipid metabolism (ko00600). No annotation was retrieved for POPTR 0008s18650 or POPTR_0017s03190, suggesting that these genes have unknown functions.

The differentially methylated genes between better- and lower-parent $F_{1}$ hybrids were also analyzed (Figure 8B). The number of hypermethylated genes of better-parent F1 hybrids versus lower-parent hybrids $\mathrm{L}_{1}$ and $\mathrm{L}_{2}$ were 523 and 132, respectively. For these genes, hypermethylation predominantly occurred in the promoter (171 genes compared with $\mathrm{L}_{1}$ and 27 genes compared with $\mathrm{L}_{2}$ ) and gene body (296 genes compared with $\mathrm{L}_{1}$ and 80 genes compared with $\mathrm{L}_{2}$ ), while less hypermethylation occurred in the 5 'UTR ( 28 genes compared with $\mathrm{L}_{1}$ and 15 genes compared with $\mathrm{L}_{2}$ ) and the 3' UTR (15 genes compared with $\mathrm{L}_{1}$ and 10 genes compared with $\mathrm{L}_{2}$ ). A total of 40 hypermethylated genes were found in all three better-parent $F_{1}$ hybrids compared with lower-parent hybrids $L_{1}$ and $\mathrm{L}_{2}$, ten of these genes could be annotated (Table 5). The $\mathrm{GO}$ functional categories of the 10 genes mainly involve metabolic process (4), primary metabolic process (2), cellular metabolic process (3), signaling (3), small molecule metabolic process (2), anatomical structure development (2), and biological regulation (2). These genes were then submitted to the KEGG Pathway database, yielding pathway information about four genes as follows: (1) POPTR_0012s07360 is calcium-dependent protein kinase gene involved in plant-pathogen interactions (ko04626); (2) POPTR_0015s09720 belongs to cytochrome P450 CYP4/CYP19/CYP26 subfamilies involved in steroid hormone biosynthesis (ko00140); (3) POPTR_0019s09910 encodes a molybdopterin synthase catalytic subunit involved in multiple processes such as metabolism, metabolism of cofactors, vitamin and folate biosynthesis (ko00790), genetic information processing, folding, sorting, and degradation, and the sulfur relay system (ko04122); and (4) POPTR_0008s18420 encodes an erbb2-interacting protein involved in a NOD-like receptor signaling pathway (ko04621). 

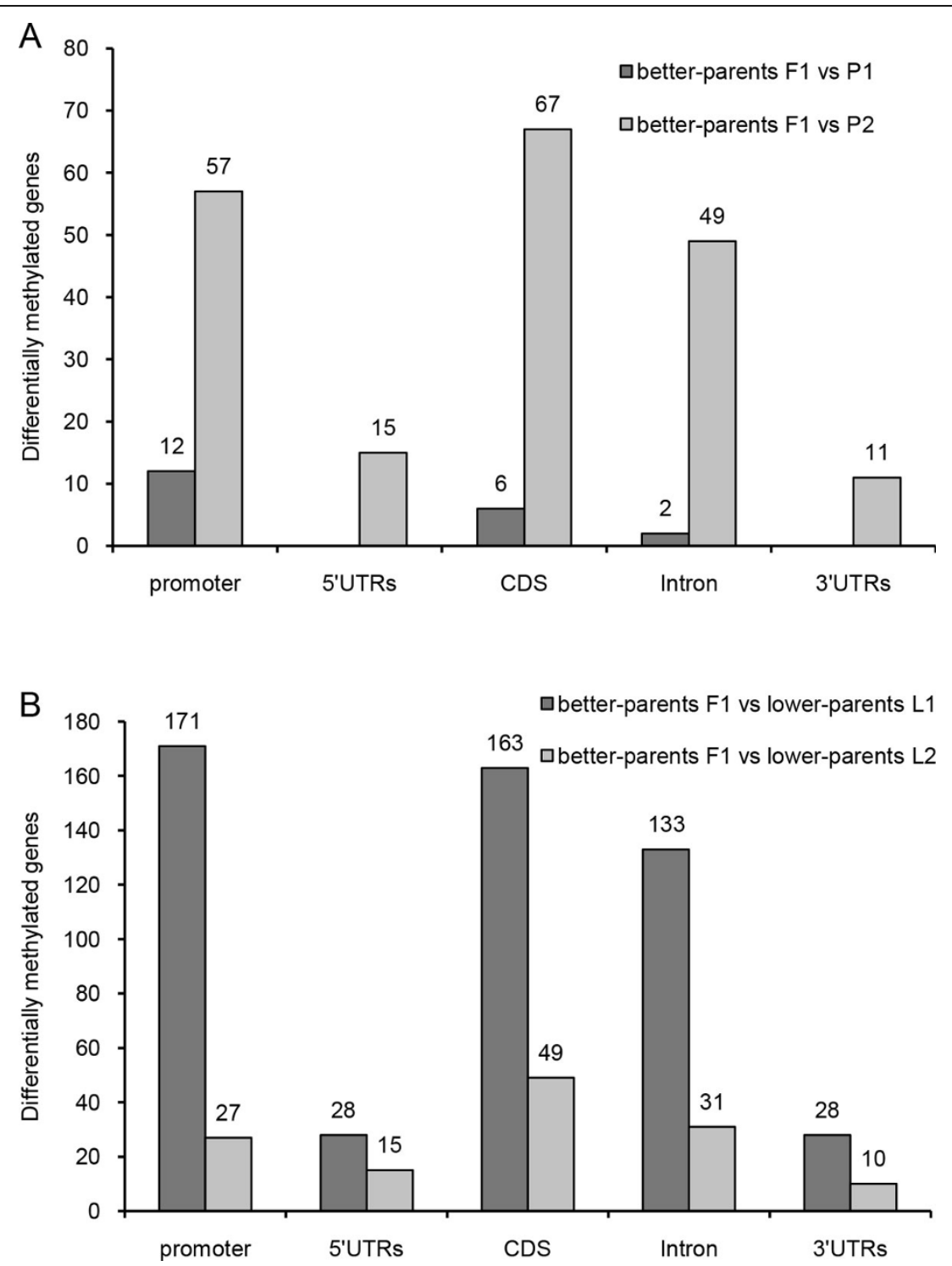

Figure 8 Comparison of differentially methylated genes in various genome features among better-parent hybrids, the parents, and lower-parent hybrids. (A) The number of differentially methylated genes between better-parent hybrids and the maternal parents were calculated (dark gray columns), and the number of differentially methylated genes between better-parent hybrids and the paternal parents are indicated in the light gray columns. (B) The number of differentially methylated genes between better-parent hybrids and below-parent hybrids L1 were calculated (dark gray columns), and the number of differentially methylated genes between better-parent hybrids and below-parent hybrids L2 are indicated in the light gray columns.

\section{Discussion}

Several classical hypotheses about heterosis are based on the differences between genomes [1], and allelic diversity may produce heterosis. However, hybrid vigor can be observed even when parents are genetically very similar [24]. Recent studies have shown that parents with similar genome sequences have distinct epigenomes, which may contribute to heterosis [5,24]. In Populus, hybrids with heterosis are often obtained by intrasection and interspecific hybridization, whereas hybrids obtained by intersection hybridization always have mid-parent performance, and hybrids with growth vigor are obtained less frequently. In Section Aigeiros, excellent hybrids with heterosis have been produced by intraspecific hybridization; the level of heterosis increases with a decrease in genetic distance between parents and polymerization of excellent genetic composition. Super high yield varieties are often generated by convergent crossing of $P$. deltoides varieties (strains). In this study, $P$. deltoides cl. ' $55 / 65$ ', was used as the maternal parent and P. deltoides cl. '10/ 17 ' was used as the paternal parent. This cross combination is a multigeneration convergent cross, and the level 
Table 5 Annotations of hypermethylated genes

\begin{tabular}{|c|c|c|c|c|c|}
\hline Gene ID & $\begin{array}{l}\text { Located } \\
\text { scaffold }\end{array}$ & $\begin{array}{l}\text { Start position of the gene } \\
\text { in the scaffold }\end{array}$ & $\begin{array}{l}\text { End position of the } \\
\text { gene in the scaffold }\end{array}$ & $\begin{array}{l}\text { Length } \\
\text { /bp }\end{array}$ & Annotation \\
\hline POPTR_0010s02290 & scaffold_10 & 2630875 & 2632874 & 2000 & $\begin{array}{l}\text { Predicted GTP-binding protein (ODN } \\
\text { superfamily) }\end{array}$ \\
\hline POPTR_0010s19920 & scaffold_10 & 17678728 & 17680727 & 2000 & Predicted 3-ketosphinganine reductase \\
\hline POPTR_0007s08200 & scaffold_7 & 6768492 & 6770491 & 2000 & Ubiquitin-like protein \\
\hline POPTR_0019s08620 & scaffold_19 & 10148682 & 10150681 & 2000 & $\begin{array}{l}\text { Cytochrome P450 CYP4/CYP19/CYP26 } \\
\text { subfamilies }\end{array}$ \\
\hline POPTR_0009s10580 & scaffold_9 & 9068290 & 9070289 & 2000 & $\begin{array}{l}\text { 15-hydroxyprostaglandin dehydrogenase } \\
\text { and related dehydrogenases }\end{array}$ \\
\hline POPTR_0012s07360 & scaffold_12 & 8260585 & 8262584 & 2000 & $\begin{array}{l}\mathrm{Ca} 2+/ \text { calmodulin-dependent protein kinase, } \\
\text { EF-Hand protein superfamily }\end{array}$ \\
\hline POPTR_0015s09720 & scaffold_15 & 10859015 & 10861014 & 2000 & Cytochrome P450 CYP2 subfamily \\
\hline POPTR_0019s02490 & scaffold_19 & 2267881 & 2269880 & 2000 & Serine/threonine protein kinase \\
\hline POPTR_0019s09910 & scaffold_19 & 11534694 & 11536693 & 2000 & $\begin{array}{l}\text { Molybdopterin converting factor, small } \\
\text { subunit }\end{array}$ \\
\hline POPTR_0008s18420 & scaffold_8 & 12397080 & 12398840 & 1761 & Leucine-rich repeat protein \\
\hline POPTR_0017s04200 & scaffold_17 & 3227408 & 3228528 & 535 & Serine/threonine protein kinase \\
\hline POPTR_0019s09760 & scaffold_19 & 11360305 & 11360904 & 600 & Apoptotic ATPase \\
\hline
\end{tabular}

The annotation of the hypermethylated genes in better-parent hybrids compared to the parents and lower-parent hybrids. These annotations were obtained according to orthologous genes in P. trichocarpa. Additional files

of heterosis is outstanding. Intraspecific F1 hybrids of $P$. deltoides with significant hybrid vigor or lower-parental performance were examined, providing a unique opportunity to accurately analyze the contribution of DNA methylation to heterosis in trees. This is the first investigation of DNA methylation maps with high resolution in P. deltoides plants and their F1 hybrids at the genome-wide scale using high-throughput sequencing.

A total of 670.55 million reads were generated using MeDIP-Seq, 486.27 million of which could be mapped onto the reference genome of $P$. trichocarpa, the average of the uniquely mapped rates was $57.8 \%$. The relatively low rate of mapping using genomes of closely related species as a reference suggests that species in different sections within the genus Populus are genetically divergent (P. trichocarpa belongs to sect. Tacamahaca, and $P$. deltoides belongs to sect. Algeiros). Similar observations were also documented in studies of Populus alba and Populus tremula based on single nucleotide polymorphism (SNP) analysis of the two species [48]. Our dataset of leaf methylomes shows that the parents and F1 hybrids had significant methylation in the CG/CHH/ CHG contexts, with $\mathrm{CHG}$ and $\mathrm{CHH}$ methylation being more consistent, and cytosines in CG context were less methylated than those in the other two contexts. Previous studies have reported that CGs are dominant in methylome, especially in coding regions, while less frequent in general, $5 \mathrm{meCHH}$ is more common in repeat regions and short transposable elements [49-51]. In populous, CG and CHG methylation were more consistent within tissues. However, in the two targets with cytosine content $<10 \%$, cytosines in $\mathrm{CHH}$ context were methylated more frequently than those in the other two contexts [34]. The two parents had distinct methylomes reflected by different methylation coverage in the CG/ $\mathrm{CHG} / \mathrm{CHH}$ contexts. The methylation coverage of three better-parent F1 hybrids was higher than the average of the parental values (mid-parent value, MPV), indicating that the F1 hybrids had an altered epigenome, and the DNA methylation level was non-additive. Unlike in animal systems, where "Erase and Reset" of cytosine methylation occurs in each generation, in plants, the parental methylation states can be stably inherited by the progeny $[52,53]$. However, many plants species often exhibit the remodeling of parental methylation patterns in interspecific hybrids and allopolyploids [54-56]. In these scenarios, DNA methylation partly functions epigenetically and dynamically over generations, thus achieving the control and balance of gene expression under specific circumstances [27,54,57].

Early studies proposed that allelic variation is the primary cause of heterosis [58], but this notion was challenged by the observation that parents with similar genetic backgrounds can also produce hybrids with heterosis, which can arise from the diversity of epialleles. Epi-allelic changes in hybrids occur though changes in siRNA levels, trans-chromosomal methylation (TCM) or trans-chromosomal demethylation (TCdM), which fit the dominance or overdominance hypotheses and indicate that epi-alleles are essential parts of the genetic basis of heterosis. In rice hybrids, DNA methylation at many loci is inherited by non-additive inheritance [29]. Although the two rice hybrids had unequal numbers of non-additively methylated loci, in both hybrids, approximately $75 \%$ of such loci 
had increased methylation levels. The increased DNA methylationwas also reported in reciprocal $\mathrm{F} 1$ hybrids between Arabidopsis thaliana Landsberg erecta and C24 [5]. In this study, we found that $P$. deltoides F1 hybrids with hybrid vigor $\left(\mathrm{H}_{1}, \mathrm{H}_{2}\right.$, and $\left.\mathrm{H}_{3}\right)$ showed higher DNA methylation coverage in three contexts than the MPV. This can partially be explained by the effects of TCM. In this scenario, the better parent derived siRNA molecules associate with both alleles, maintains the methylation state of its own alleles and establishes the de novo methylation of lower parent hypomethylation [24], resulting in increased methylation levels in the non- or low methylation region. Therefore, the methylation levels of hybrids may exceed MPV. For lower-parent hybrids $L_{1}$, the fact that DNA methylation coverages in three contexts are lower than parental values can be attributed to the influence of TCdM. The lower parent derived siRNA initially becomes associated across both parental alleles. This association can cause siRNA level to be present at lower levels than the threshold required for the establishment and/or maintenance of methylation, leading to hypomethylation of alleles of the lower parent allele. At the same time, with the loss of methylation, normal siRNA levels cannot be maintained (loss of siRNA), which further reduces the level of DNA methylation, as detected in the lower-parent hybrids $\mathrm{L}_{1}$ with lower methylation levels. Thus, contrasting patterns of methylation between poplar better-parent F1 and lower-parent $\mathrm{L}_{1}$ hybrids may result from an adjustment of methylation levels of the parents, and this difference in methylation may in turn influence and regulate the expression network of target genes, which is beneficial to the establishment of heterosis. Interestingly, one of the hybrids with negative better-parent heterosis $\left(\mathrm{L}_{2}\right)$ has methylation coverages in three contexts above the midparent value, and the variations in methylation in specific genomic features (such as intron) and in transposable elements and repetitive sequences seem dependent on each genotype. This indicates that the role of DNA methylation in heterosis is complex and multifaceted.

In addition, in some annual herb plant species, distinct epigenomes between parents can give rise to increased DNA methylation levels in the F1 hybrids and contribute to heterosis. For instance, when two rice subspecies, Nipponbare (o. sativa ssp japonica) and 93-11 (o. sativa ssp indica), were used as parents, 82.1 and $70.8 \%$ of the different methylation region (DMRs) of the genome of F1 hybrids showed high- or above high-parental DNA methylation levels, respectively [29]. When A. thaliana Landsberg erecta and C24 were used as parental lines, the reciprocal F1 hybrids showed increased DNA methylation levels across the entire genome, especially in the transposable elements [5].

However, other studies revealed no obviously altered or decreased methylation levels in hybrids compared with their parents. In Arabidopsis thaliana, 97\% of the $M s p \mathrm{I} / H p$ aII recognition sites in the F1 hybrids of a Col-0 and C24 cross retained their levels of methylation [59]. The methylation levels of cotton hybrids were lower than those of the parents, and the demethylation numbers of better-parent hybrids were higher than those of the lower-parent hybrids [60]. This discrepancy may be due to the different approaches used in these two studies versus the present study. The two previous studies used a methylation-sensitive amplified polymorphism assay, which is much less sensitive than MeDIP-Seq and thus could not fully scan all methylation loci and could only partially provide the landscapes of DNA methylation.

The MACS approach can improve the spatial resolution of the aligned data and impart the robustness of the final aligned sequences based on dynamic Poisson distribution [39]. The peak coverage further illustrates that the parents had distinct DNA methylation levels, while F1 hybrids with hybrid vigor possessed elevated DNA methylation levels, and F1 hybrids with negative hybrid vigor possessed declining DNA methylation levels. In the $P$. deltoides genomes, peak data were found to be more enriched in promoters than in gene bodies, and the CDS showed more enrichment than introns or UTRs in gene bodies. The enrichment levels of various genomic features in the better-parent hybrids, parent and lowerparent hybrid were different. The growth vigor displayed in better-parent hybrids may be attributed to the increased transcriptional inactivation of CG and CHG sites and heterochromatin-mediated gene silencing, which are related to methylated enrichment. Throughout the growth and development of poplar, methylated enrichment may also suppress the expression of a proportion of genes and/or reduce spurious global transcription to enable full transcription or to initiate the expression of other suitable loci, consequently increasing hybrid vigor in the F1 hybrids; this concept deserves further investigation.

The analysis of differentially methylated genes between parents and hybrids has revealed that the hypermethylation levels of better-parent F1 hybrids were between those of the two parents, while the hypermethylation levels of the lower-parent F1 hybrids was lower than lowest value of the parents. This finding suggests that having a methylation level between that of the two parents in F1 hybrids may be more favorable for achieving better-parent heterosis, while deviating from the MPV tends to preclude the establishment of heterosis.

The analysis of GO functional categories showed that the differentially methylated genes between the betterparent F1 hybrids and the parents were enriched in metabolic processes, response to stress, and binding and catalytic activity, which indicates that heterosis in trees 
may follow a comprehensive process. At the same time, compared with lower-parent F1 hybrids, the hypermethylated genes in the better-parent F1 hybrids were enriched in metabolic and development processes, such as metabolic process, cellular metabolic process, primary metabolic process, small molecule metabolic process, nitrogen compound metabolic process, developmental process, anatomical structure development, and signaling, which implied that differentially methylated genes are involved in heterosis.

Compared with the parents and lower-parent F1 hybrids, the hypermethylated genes in better-parent F1 hybrids were involved in hormone synthesis and response to stress, such as cytochrome P450, participating in the biosynthesis of hormones, defensive compounds and fatty acids, GTP-binding proteins involved in cytoskeleton organization, signal transduction, vesicle trafficking, and stress tolerance. As $\mathrm{Ca}^{2}{ }^{+}$signal transducers, calcium-dependent protein kinases play an important role in various plant physiological process, including growth, development, defense responses, regulation of reactive oxygen species production, symbiotic interactions, guard cell turgor, osmotic, drought and salt stress, and regulation through hormones such as ABA and GA. In summary, the fact that many differentially methylated genes are involved in diverse biological pathways indicates that the inheritance of heterosis is a multidimensional process.

\section{Conclusions}

To date, studies linking epigenetics and heterosis have only been carried out in a few plant species. In this study, we identified genome-wide variations in leaf methylomes between parents and their hybrids in P. deltoides, a perennial forest tree species. The dataset derived from MeDIP-Seq were used to produce DNA methylation maps with high resolution of $P$. deltoides. cl. '55/65' and P. deltoides cl. '10/17' and their five F1 hybrids. Populus F1 hybrids has a non-additive mathylation level (higher than mid-parent values), which showed that the methylation patterns of the parents partially and dynamically passed onto their hybrids and was remodeled. In addition, the DNA methylomes of betterparent F1 hybrids were significantly different from that of lower-parent F1 hybrids, which indicates that having a methylation level between that of the two parents may be more favorable for the achievement of better-parent heterosis in F1 hybrids, while the deviation from MPV tends to preclude the establishment of heterosis. Compared with the parents and the lower-parent F1 hybrids, the hypermethylated genes in the better-parent F1 hybrids were enriched in the processes of metabolism and development, which may be highly relevant to heterosis.

\section{Additional material}

Additional file 1: Additional file 1 includes Table $S 1$, which gives detailed information about the growth comparisons between the parents and F1 hybrids. Tree height and DBH were measured during five successive years. Means are given with \pm SE. Different letters indicate significant difference $(P<0.05)$ among the lines in trees of the same age.

Additional file 2: Additional file 2 includes Figure S1 and Figure S2. Figure S1 describes the trend of average coverage depth of DNA methylation in the intragenic region. The region within the dotted line indicates intragenic region. 2,000-bp regions upstream and downstream of intragenic are divided into 20 segments, and the intragenic are divided into 40 segments. Figure S2 provides details of $\mathrm{GO}$ analysis of differentially methylated genes. (A) GO analysis of differentially methylated genes between the maternal parent and better-parent F1 hybrids. Three comparison pairs ( $\mathrm{H} 1$ versus $\mathrm{P} 1, \mathrm{H} 2$ versus $\mathrm{P} 1$, and $\mathrm{H} 3$ versus $P 1$ were included in this analysis. (B) GO analysis of differentially methylated genes between the paternal parent and better-parent F1 hybrids. $\mathrm{H} 1$ versus $\mathrm{P} 2, \mathrm{H} 2$ versus $\mathrm{P} 2$, and $H 3$ versus $\mathrm{P} 2$ were included in this analysis. (C) GO analysis of differentially methylated genes between the maternal parent and lower-parent F1 hybrids. Two comparison pairs ( $L 1$ versus P1, $L 2$ versus $P 1$ ) were included in this analysis. (D) $G O$ analysis of differentially methylated genes between the paternal parent and lower-parent F1 hybrids. L1 versus P2 and L2 versus P2 were included in this analysis.

\section{Competing interests}

The authors declare that they have no competing interests.

\section{Authors' contributions}

GM and HQ carried out the experiments and performed manuscript draft writing. GM, HQ and CY performed bioinformatics and statistical analysis. DC and ZB participated in the design and coordination the study. SX designed the study and revised this manuscript. All authors read and approved the final manuscript.

\section{Declarations}

The publication charges this article were funded by the National Key Technology Research and Development Program for the Twelfth Five-YearPlan of China (Grant No. 2012BAD01B03) and National Key Technology Research and Development Program for the Eleventh Five-Year-Plan of China (Grant No. 2006BAD01A15).

This article has been published as part of BMC Genetics Volume 15 Supplement 1, 2014: Selected articles from the International Symposium on Quantitative Genetics and Genomics of Woody Plants. The full contents of the supplement are available online at http://www.biomedcentral.com/ bmcgenet/supplements/15/S1.

\section{Authors' details}

${ }^{1}$ State Key Laboratory of Tree Genetics and Breeding, Research Institute of Forestry, Chinese Academy of Forestry, 100091 Beijing, P.R. China. ${ }^{2}$ Key Laboratory of Tree Breeding and Cultivation, State Forestry Administration, 100091 Beijing, P.R. China.

Published: 20 June 2014

\section{References}

1. Birchler JA, Auger DL, Riddle NC: In search of the molecular basis of heterosis. Plant Cell 2003, 15:2236-2239.

2. Birchler JA, Yao H, Chudalayandi S, Vaiman D, Veitia RA: Heterosis. Plant Cell 2010, , 22: 2105-2112.

3. Hochholdinger F, Hoecker N: Towards the molecular basis of heterosis. Trends in Plant Science 2007, , 12: 427-432.

4. Chen ZJ: Molecular mechanisms of polyploidy and hybrid vigor. Trends in Plant Science 2010, 15:57-71.

5. Shen H, He H, Li J, Chen W, Wang X, Guo L, Peng Z, He G, Zhong S, Qi Y, et al: Genome-wide analysis of DNA methylation and gene expression 
changes in two arabidopsis ecotypes and their reciprocal hybrids. Plant cell 2012, 24:875-892.

6. Roberts: Plant Hybridization before Mendel Princeton, NJ: Princeton University Press; 1929.

7. Reif JC, Warburton ML, Xia XC, Hoisington DA, Crossa J, Taba S, Muminović J, Bohn M, Frisch M, Melchinger AE: Grouping of accessions of Mexican races of maize revisited with SSR markers. Theoretical and Applied Genetics 2006, 113: 177-185.

8. Nakamura S, Hosaka K: DNA methylation in diploid inbred lines of potatoes and its possible role in the regulation of heterosis. Theoretical and Applied Genetics 2010, 120: 205-214.

9. He G, Elling AA, Deng XW: The epigenome and plant development. Annual Review of Plant Biology 2010, 62:411-435.

10. Lippman ZB, Zamir D: Heterosis: revisiting the magic. Trends in Genetics 2007, 23:60-66.

11. Swanson-Wagner RA, Jia Y, DeCook R, Borsuk LA, Nettleton D, Schnable PS: All possible modes of gene action are observed in a global comparison of gene expression in a maize $\mathrm{F} 1$ hybrid and its inbred parents. Proceedings of the National Academy of Sciences, USA 2006, , 103: 6805-6810.

12. Swanson-Wagner RA, DeCook R, Jia Y, Bancroft T, Ji T, Zhao X, Nettleton D, Schnable PS: Paternal dominance of trans-eQTL influences gene expression patterns in maize hybrids. Science 2009, 326: 1118-1120

13. Paschold A, Marcon C, Hoecker N, Hochholdinger F: Molecular dissection of heterosis manifestation during early maize root development. Theoretical and Applied Genetics 120:441-450.

14. Meyer S, Pospisil H, Scholten S: Heterosis associated gene expression in maize embryos 6 days after fertilization exhibits additive, dominant and overdominant pattern. Plant Molecular Biology 2007, 63:381-391.

15. Zhang $H Y$, He $H$, Chen $L B$, Li L, Liang MZ, Wang XF, Liu XG, He GH, Chen $R S, M a L G$, et al: A genome-wide transcription analysis reveals a close correlation of promoter INDEL polymorphism and heterotic gene expression in rice hybrids. Molecular Plant 2008, 1:720-731

16. Wei G, Tao Y, Liu G, Chen C, Luo R, Xia H, Gan Q, Zeng H, Lu Z, Han Y, et al: A transcriptomic analysis of superhybrid rice LYP9 and its parents. Proceedings of the National Academy of Sciences, USA 2009, 106:7695-7701.

17. Andorf S, Selbig J, Altmann T, Poos K, Witucka-Wall H: Enriched partial correlations in genome-wide gene expression profiles of hybrids (A. thaliana): A systems biological approach towards the molecular basis of heterosis. Theoretical and Applied Genetics 2010, 120:249-259.

18. Wang Z, Ni Z, Wu H, Nie X, Sun Q: Heterosis in root development and differential gene expression between hybrids and their parental inbreds in wheat (Triticum aestivum L.). Theoretical and Applied Genetics 2006, 113:1283-1294.

19. Li A, Fang MD, Song WQ, Chen CB, Qi LW, Wang CG: Gene expression profiles of two intraspecific Larix lines and their reciprocal hybrids. Molecular Biology Reports 2012, 4:3773-3784.

20. Zhuang $Y$, Adams KL: Extensive allelic variation in gene expression in Populus F1 hybrids. Genetics 2007, 177:1987-1996.

21. Jin H, Hu W, Wei Z, Wan L, Li G, Tan G, Zhu L, He G: Alterations in cytosine methylation and species-specific transcription induced by interspecific hybridization between Oryza sativa and 0 . officinalis. Theoretical and Applied Genetics 2008, 117:1271-1279.

22. Takamiya T, Hosobuchi S, Noguchi T, Asai K, Nakamura E, Habu Y, Paterson $\mathrm{AH}$, lijima $\mathrm{H}$, Murakami $\mathrm{Y}$, Okuizumi $\mathrm{H}$ : Inheritance and alteration of genome methylation in F1 hybrid rice. Electrophoresis 2008, 29:4088-4095

23. Zhang MS, Yan HY, Zhao N, Lin XY, Pang JS: Endosperm-specific hypomethylation, and meiotic inheritance and variation of DNA methylation level and pattern in sorghum (Sorghum bicolor L.) interstrain hybrids. Theoretical and Applied Genetics 2007, 115:195-207.

24. Groszmann M, Greaves IK, Albertyn ZI, Scofield GN, Peacock WJ, Dennis ES: Changes in 24-nt siRNA levels in Arabidopsis hybrids suggest an epigenetic contribution to hybrid vigor. Proceedings of the National Academy of Sciences, USA 2011, 108:2617-2622.

25. and Colot V: DNA methylation and epigenetic inheritance in plants and filamentous fungi. Science 2001, , 293: 1070-1074.

26. Bird A: DNA methylation patterns and epigenetic memory. Genes \& Development 2002, 16: 6-21.

27. Chan SW, Henderson IR, Jacobsen SE: Gardening the genome:DNA methylation in Arabidopsis thaliana. Nature Reviews Genetics 2005, 6:351-360
28. Law JA, Jacobsen SE: Establishing, maintaining and modifying DNA methylation patterns in plants and animals. Nature Reviews Genetics 2010, 11: 204-220.

29. He G, Zhu X, Elling A, Chen L, Wang $X$, Guo L, Liang M, He H, Zhang H, Chen $F$, et al: Global epigenetic and transcriptional trends among two rice subspecies and their reciprocal hybrids. Plant Cell 2010, 22:17-33.

30. Hamanishi ET, Campbell MM: Genome-wide responses to drought in forest trees. Forestry 2011, , 84: 273-283.

31. Lafon-Placette C, Faivre-Rampant P, Delaunay A, Street N, Brignolas F, Maury S: Methylome of DNase I sensitive chromatin in Populus trichocarpa shoot apical meristematic cells: a simplified approach revealing characteristics of gene-body DNA methylation in open chromatin state. New Phytologist 2013, 197:416-30.

32. Gourcilleau D, Bogeat-Triboulot M-B, Le Thiec D, Lafon-Placette C, Delaunay A, El-Soud WA, Brignolas F, Maury S: DNA methylation and histone acetylation: genotypic variations in hybrid poplars, impact of water deficit and relationships with productivity. Annals of Forest Science 2010, 67:208.

33. Raj S, Brautigam K, Hamanishi ET, Wilkins O, Thomas BR, Schroeder W, Mansfield SD, Plant AL, Campbell MM: Clone history shapes Populus drought responses. Proceedings of the National Academy of Sciences, USA 2011, 108:12521-12526.

34. Vining KJ, Pomraning KR, Wilhelm $L$, Priest HD, Pellegrini M, Mockler TC, Freitag M, Strauss SH: Dynamic DNA cytosine methylation in the Populus trichocarpa genome: tissue-level variation and relationship to gene expression. BMC Genomics 2012, 13:27.

35. Xiao J, Li J, Yuan L, McCouch SR, Tanksley SD: Genetic diversity and its relationship to hybrid performance and heterosis in rice as revealed by PCR-based markers. Theoretical and Applied Genetics 1996, 92:637-643.

36. Pomraning KR, Smith KM, Freitag M: Genome-wide high throughput analysis of DNA methylation in eukaryotes. Methods 2009, 47:142-150.

37. Sati S, Tanwar VS, Kumar KA, Patowary A, Jain V, Ghosh S, Ahmad S, Singh M, Chandak GR, et al: High Resolution Methylome Map of Rat Indicates Role of Intragenic DNA Methylation in Identification of Coding Region. PLOS ONE 2012, 7(2):e31621, doi:10.1371/journal.pone.0031621.

38. Li R, Yu C, Li Y, Lam TW, Yiu SM, Kristiansen K, Wang J: SOAP2: an improved ultrafast tool for short read alignment. Bioinformatics 2009, 25:1966-1967.

39. Zhang Y, Liu T, Meyer CA, Eeckhoute J, Johnson DS, Bernstein BE, Nussbaum C, Myers RM, Brown M, Li W, et al: Model-based analysis of ChIP-Seq (MACS). Genome Biology 2008, 9:R137.

40. Henderson IR, Jacobsen SE: Epigenetic inheritance in plants. Nature 2007, 447: 418-424

41. Ashikawa I: The Gene-associated CpG islands in plants as revealed by analyses of genomic sequences. The Plant Journal 2001, 26:617-625.

42. Yamada Y, Watanabe H, Miura F, Soejima H, Uchiyama M, Iwasaka T, Mukai T, Sakaki Y, Ito T: A comprehensive analysis of allelic methylation status of CpG islands on human chromosome 21q. Genome Research 2004, 14: 247-266.

43. Straussman R, Nejman D, Roberts D, Steinfeld I, Blum B, Benvenisty N, Simon I, Yakhini Z, Cedar H: Developmental programming of $\mathrm{CpG}$ island methylation profiles in the human genome. Nature Structural \& Molecular Biology 2009, , 16: 564-571.

44. Feber A, Wilson GA, Zhang L, Presneau N, Idowu B, Down TA, Rakyan VK, Noon LA, Lloyd AC, Stupka E, et al: Comparative methylome analysis of benign and malignant peripheral nerve sheath tumors. Genome Research 2011, 21:515-524.

45. Douglas C, DiFazio S: Genetics and Genomics of Populus. In The Populus genome and comparative genomics. Berlin: Springer-Verlag;Jansson S, Bhalerao R, Groover A 2010:67-90.

46. Wootton JC, Federhen S: Statistics of local complexity in amino acid sequences and sequence databases. Computers \& chemistry 1993, 17(2):149-163.

47. Price AL, Jones NC, Pevzner PA: De novo identification of repeat families in large genomes. Bioinformatics 2005, 21(suppl 1):i351-i358.

48. Stölting KN, Nipper R, Lindtke D, Caseys C, Waeber S: Genomic scan for single nucleotide polymorphisms reveals patterns of divergence and gene flow between ecologically divergent species. Molecular Ecology 2012, 22:842-855

49. Cokus SJ, Feng S, Zhang X, Chen Z, Merriman B, Haudenschild CD, Pradhan S, Nelson SF, Pellegrini M, Jacobsen SE: Shotgun bisulphite 
sequencing of the Arabidopsis genome reveals DNA methylation patterning. Nature 2008, 452(7184):215-219.

50. Widman N, Jacobsen SE, Pellegrini M: Determining the conservation of DNA methylation in Arabidopsis. Epigenetics 2009, 4(2):119-124.

51. Cokus SJ, Feng S, Zhang X, Chen Z, Merriman B, Haudenschild CD, Pradhan S, Nelson SF, Pellegrini M, Jacobsen SE: Shotgun bisulphite sequencing of the Arabidopsis genome reveals DNA methylation patterning. Nature 2008, 452(7184):215-219.

52. Cubas $P$, Vincent $C$, Coen E: An epigenetic mutation responsible for natural variation in floral symmetry. Nature 1999, 401:157-161.

53. Kakutani T: Epi-alleles in plants: inheritance of epigenetic information over generations. Plant and Cell Physiology 2002, 43:1106-1111.

54. Madlung A, Masuelli RW, Watson B, Reynolds SH, Davison J, Comai L: Remodeling of DNA methylation and phenotypic and transcriptional changes in synthetic Arabidopsis allotetraploids. Plant Physiology 2002, 129:733-746.

55. Lukens LN, Pires JC, Leon E, Vogelzang R, Oslach L, Osborn T: Patterns of sequence loss and cytosine methylation within a population of newly resynthesized Brassica napus allopolyploids. Plant Physiology 2006, 140:336-348.

56. Marfil CF, Masuelli RW, Davison J, Comai L: Genomic instability in Solanum tuberosum Solanum kurtzianum interspecific hybrids. Genome 2006 49:104-113.

57. Zhang MS, Yan HY, Zhao N, Lin XY, Pang JS: Endosperm-specific hypomethylation and meiotic inheritance and variation of DNA methylation level and pattern in sorghum (Sorghum bicolor L.) interstrain hybrids. Theoretical and Applied Genetics 2007, 115:195-207.

58. Sakthivel K, Girishkumar K, Ramkumar G, Shenoy W, Kajjidoni ST: Alterations in inheritance pattern and level of cytosine DNA methylation, and their relationship with heterosis in rice. Euphytica 2010, 175:303-314.

59. Banaei MAM, Fuchs J, Czauderna T, Houben A, Mette MF: Intraspecific hybrids of Arabidopsis thaliana revealed no gross alterations in endopolyploidy, DNA methylation, histone modifications and transcript levels. Theoretical and Applied Genetics 2010, 120:215-226

60. Zhao Y, Yu S, Xing C, Fan S, Song M: DNA methylation in cotton hybrids and their parents. Mlekuliarnaia biologiia 2008, , 42: 195-205.

doi:10.1186/1471-2156-15-S1-S8

Cite this article as: Gao et al:: Analysis of the leaf methylomes of parents and their hybrids provides new insight into hybrid vigor in Populus deltoides. BMC Genetics 2014 15(Suppl 1):S8.

\section{Submit your next manuscript to BioMed Central and take full advantage of:}

- Convenient online submission

- Thorough peer review

- No space constraints or color figure charges

- Immediate publication on acceptance

- Inclusion in PubMed, CAS, Scopus and Google Scholar

- Research which is freely available for redistribution

Submit your manuscript at www.biomedcentral.com/submit
Biomed Central 